\title{
Screening, Gene Sequencing and Biosurfactant Production from Pichia Fermentans Isolated From Dairy Effluents
}

\author{
Jolly Mariam Johny*1 \\ ${ }^{1}$ Department of Microbiology, Bharathiar University, Coimbatore
}

\begin{abstract}
Microbial surfactants are surface metabolites that produced by bacteria, yeast, and fungi having varied chemical structure and properties. These molecules reduce surface tension between aqueous solutions and hydrocarbon mixtures. Recently biosurfactants are potential alternatives for chemically synthesized surfactants having varied industrial applications. In this study, we collected fermented dairy whey waste samples from a small dairy farm house located in Salem and Coimbatore and a total of fifty yeast strains were isolated, screened for biosurfactant activity, and cultured by enriching carbon and nitrogen sources. These were conducted using oil displacement technique, drop collapse method, microplate assay method, and emulsification activity determination (EA). Among fifty isolates, SS2 yeast strains exhibited positive for biosurfactant activity. . The yeast strain SS2 exhibited an oil clearance diameter of $12 \mathrm{~mm}$ with an interpolated surfactant concentration of 2.77 micrograms and measured an emulsification index is 61.42 with a height of emulsion $17.2 \mathrm{~mm}$ after 120 hours. Biochemical analysis and molecular characterization with $18 S \mathrm{~S}$ RNA gene sequence indicates that yeast strain SS2 belongs to Pichia species and closely related to Pichia fermentans. Studies of biosurfactant production on various carbon and nitrogen sources were performed. The communication looks at the future perspective of biosurfactant production and its application in the healthcare and pharmaceutical sector.
\end{abstract}

Keywords: Microbial surfactants, $18 S$ rRNA-ITS gene sequencing, Pichia fermentans

\section{Introduction}

Microbial surfactants are important biotechnological products with a wide range of applications in many industries such as food, cosmetics, and pharmaceutical industries [1]. These surfactants are produced by a variety of microorganisms, secreted either extracellular or attached to parts of cells, predominantly during growth on water immiscible substrates. They are categorized mainly by their chemical composition and their microbial origins. The microbial surfactants are structurally diverse group of surface active molecule which can be categorized as glycolipids, lipopeptides, fatty acids, polysaccharide-protein complexes, phospholipids, peptides, and neutral lipids [2]. These amphiphilic compounds contain a hydrophobic and a hydrophilic moiety, and have the ability to reduce the interfacial tension between different fluid phases. It is less toxic, highly biodegradable, with better environmental compatibility, high foaming and selectivity, and specific at extreme temperature, $\mathrm{pH}$, and salinity [3]. These molecules reduce surface and interfacial tensions in both aqueous solution and hydrocarbon mixtures [4]. Its biodegradability, ecological safety, production from renewable resources, and functionality under extreme conditions make these microbial surface active agents superior to chemical surfactants [5]. The surface active compounds commonly used in medical and industrial applications are chemically synthesized which can be replaced by biosurfactants produced from microorganisms $[6,7]$. The surfactant market exceeds US $\$ 9.4$ billion per annum with the demand expected to increase at the rate of $35 \%$ per year. According to the Technical Insight, a division of Frost \& Sullivan, microbial surfactants have begun to enjoy a market [8]. According to the Transparency Market Research, the global biosurfactant market was worth USD 1,735.5 million in 2011 and is expected to reach USD 2, 210.5 million in 2018, growing at a CAGR of $3.5 \%$ from 2011 to 2018 [9]. Many studies point out to the increased demand for synthetic surfactants globally in spite of that being a reason for an environmental hazard. Minimal studies have been reported on microbial surfactants synthesized by yeasts [10], and most of them are related to bacteria [11]. Recently yeasts are known for producing microbial surface active agents in higher concentration than bacteria, especially due to their GRAS (generally regarded as safe) status [12]. The microorganisms use agro-industrial wastes as carbon sources and several other renewable substrates for the production of microbial surfactants. The choice of cheap raw materials is important to the overall economy of the process and also reduces the expenses with waste treatment [13]. The usages of low cost substrates as carbon sources make the production of microbial surfactants economically viable. Agricultural wastes, fermented whey waste, effluents from food industries, and residual waste containing high levels of carbohydrates and lipids with reduced production costs and minimal volume of waste dumped into the environment [14]. The effluents of vegetable oil industries, petrochemical oil residues or by the byproducts from the food industries have been extensively studied for microbial production at an experimental scale [15]. Recently there has been worldwide interest on molecular techniques [16]. 
Amplification and sequencing of target regions within the ribosomal DNA has emerged as a useful tool for the identification of yeast strains [17].

The present work was done to assess, isolate, and select yeast strains from fermented dairy whey waste (effluent), collected from in and around Coimbatore and Salem districts, which possesses a potential for the production of biosurfactant.

\subsection{Sample collection and microbial culture maintenance}

\section{Materials and Methods}

Fermented dairy whey waste was collected from a small dairy farm house located in Mettur, Salem district and Avinashi, Coimbatore and stored at $4{ }^{\circ} \mathrm{C}$ until analysis. The collected sample were serially diluted in buffered peptone sodium chloride solution $(\mathrm{pH} 7)$ and pour plate technique was performed and inoculated into Yeast Extract Peptone Dextrose (YEPD) and Rose Bengal Chloramphenicol agar (RBCA) and incubated at $30^{\circ} \mathrm{C}$ for $48 \mathrm{hr}$. Transfers were done to fresh agar slants each month to maintain viability.

\subsection{Isolation of biosurfactant producing yeast strains}

Screening for a total of fifty colonies with yeast like colony morphology were stained and observed. Yeast like cells were subcultured and maintained in YEPD and transfers were done to fresh agar slants to maintain viability. All chemicals used for the work were of analytical grade and media components were purchased from Hi-media (Mumbai, India). To determine the biosurfactant production ability, a total of fifty yeast isolates were inoculated into mineral salt medium $\left(2.5 \mathrm{~g} / 1\right.$ of $\mathrm{NaNO}_{3}, 0.1 \mathrm{~g} / 1 \mathrm{~g}$ KCL, $3.0 \mathrm{~g} / 1$ of $\mathrm{KH}_{2} \mathrm{PO}_{4}$, $7.0 \mathrm{~g} / \mathrm{l}$ of $\mathrm{K}_{2} \mathrm{HPO}_{4}, 0.01 \mathrm{~g} / \mathrm{l}$ of $\mathrm{CaCl}_{2}, 0.5 \mathrm{~g} / \mathrm{l}$ of $\left.\mathrm{MgSO}_{4} .7 \mathrm{H}_{2} \mathrm{O}\right)$ supplemented with $5 \mathrm{ml}$ of trace element solution $\left(0.116 \mathrm{~g} / \mathrm{l}\right.$ of $\mathrm{FeSO}_{4} .7 \mathrm{H}_{2} \mathrm{O}, 0.232 \mathrm{~g} / \mathrm{l}$ of $\mathrm{H}_{3} \mathrm{BO}_{3}, 0.41 \mathrm{~g} / \mathrm{l}$ of $\mathrm{CoCl}_{2} .6 \mathrm{H}_{2} \mathrm{O}, 0.008 \mathrm{~g} / \mathrm{l}$ of $\mathrm{CuSO}_{4} .5 \mathrm{H}_{2} \mathrm{O}, 0.008 \mathrm{~g} / \mathrm{l}$ of $\mathrm{MnSO}_{4} \cdot \mathrm{H}_{2} \mathrm{O}, 0.022 \mathrm{~g} / \mathrm{l}$ of $\left[\mathrm{NH}_{4}\right]_{6} \mathrm{Mo}_{7} \mathrm{O}_{24}, 0.174 \mathrm{~g} / 1$ of $\left.\mathrm{ZnSO}_{4}\right)$ and final $\mathrm{pH}$ was adjusted to 7.0. Five percent of the inoculums were inoculated into MSM medium containing $2 \%$ of a mixture of fermented whey wastewater and glucose as a source of carbon and energy source, incubated at $200 \mathrm{rpm}$ at $30^{\circ} \mathrm{C}$ for 7 days. The culture suspension was then subjected for screening the biosurfactant production capacity of yeast isolates.

\subsection{Biochemical analysis of SS2 yeast isolate}

Yeast strain SS2 was isolated, identified by physiological activities and biochemical characteristics and confirmed by the Internal Transcribed Spacer (ITS) rDNA sequence analysis. Yeast Nitrogen base broth (YNB) was used. YNB broth was prepared by adding following ingredients: (g/l) Ammonium sulfate 5g, KH2PO4 1g, MgSO4 5g, $\mathrm{NaCl} 0.1 \mathrm{~g}, \mathrm{CaCl} 20.1 \mathrm{~g}$, Inositol $0.002 \mathrm{~g}$. The medium was filter sterilized with $1 \%$ Carbohydrate used in the experiment. After sterilization the media was added into microtiter plates and inoculated with the respective isolates and incubated for 24 to $48 \mathrm{hr}$ at $30^{\circ} \mathrm{C}$.

\subsection{Identification of SS2 yeast isolate using 18S -ITS sequence of rRNA based molecular technique}

Samples of the isolates were sent to Aristogene Biotech at Bangalore for molecular characterization. Fungal DNA was isolated from the respective isolate that showed positive biochemical analysis. DNAZol method [18] was carried out for yeast DNA isolation. The yeast cell pellet was with $0.5 \mathrm{ml}$ of PBS, centrifuged for five minutes at $6000 \mathrm{rpm}$. Pellets were dispersed and treated with $3 \mathrm{ul}$ of $10 \mathrm{mg} / \mathrm{ml}$ Proteinase $\mathrm{K}$ for 30 minutes at $65^{\circ} \mathrm{C}$. Then $0.5 \mathrm{ml}$ of DNAzol was added and incubated at $45^{\circ} \mathrm{C}$ for one hour with intermittent mixing. This was centrifuged at high speed for fifteen minutes and supernatant was transferred into fresh vial. Equal volumes of isopropanol was added and mixed well. It was then centrifuged at high speed for fifteen minutes and supernatant was discarded. To the pellet, $70 \%$ ethanol was added and centrifuged. Then pellet were air dried and suspended in $30 \mu \mathrm{l}$ of TE. Silica spin columns and buffers were obtained from Qiagen. Following lysis, purification and quantification of eluted DNA samples were done by loading into the Agrose gel [19]. 18s rRNA gene primers were used to amplify $\sim 1.1 \mathrm{~Kb}$ gene from the genomic DNA isolated. Both forward and reverse primers were used for species identification according to the method suggested by Olmos et al, 2002 [20]. PCR product obtained was gel purified, quantified, and sent for sequencing. The analysis of nucleotide sequence was done in Blast-n site at NCBI server (http://www.ncbi.nlm.nih.gov/BLAST) and consensus sequence generated from forward and reverse sequences using Aligner software. This sequence was subjected to BLAST with NCBI Genbank database. A phylogenetic tree was constructed for SS2 yeast sequence.

\subsection{Preliminary screening for biosurfactant activity}

The culture supernatant was tested for biosurfactant activity by oil spreading technique, drop collapse technique, and Microplate assay method.

Oil displacement technique: For the oil spreading technique, $50 \mathrm{ml}$ of distilled water was added to a large petri dish followed by addition of $20 \mu 1$ of crude oil to the surface of the water. Ten microliters of culture were then added to the surface of oil [21]. The diameter of the clear zone on the oil surface was measured. The 
diameters of duplicate samples from the same culture of each strain were determined. The unknown biosurfactant concentration was determined by comparing with the concentration of the standard surfactant Tween-80 in various dilutions and a standard graph was plotted.

Drop collapse technique: For this technique, each well was coated with $7 \mu 1$ mineral oil and left for 24 $\mathrm{hr}$ at room temperature. After that, $20 \mu \mathrm{l}$ of supernatant and $20 \mu \mathrm{l}$ of each control solution were added to each well by the syringe at an angle of $45^{\circ}$. After $1 \mathrm{~min}$ the drops were examined visually. The syringe was rinsed three times with distilled water, three times with alcohol and three times with ether between each measurement. All experiments were repeated three times. Biosurfactant-producing cultures gave flat drops with scoring system ranging from ' + ' to ' ++++ ' corresponding to partial to complete spreading on the oil surface. Aliquots from a culture of each strain were analyzed on two separate microtiter plates [22].

Microplate assay technique: The surface activity of individual strains can be determined qualitatively with the microplate assay technique developed and patented by Vaux and Cottingham [23]. This assay is based on the change in optical distortion that is caused by surfactants in an aqueous solution. Pure water in a hydrophobic well has a flat surface. The presence of surfactants causes some wetting at the edge of the well and the fluid surface becomes concave and takes the shape of a diverging lens. For this assay, a $100 \mu 1$ sample of the supernatant of each strain is taken and put into a microwell of a 96-mircowell plate. The plate is viewed using a backing sheet of paper with a grid.

\subsection{Emulsification activity and emulsification index calculation}

The results of preliminary screening indicated highest biosurfactant producing activity in SS2 yeast isolate, among fifty isolates. Emulsification activity was done for qualitative analysis of its biosurfactant producing property. It was determined by the addition of $2 \mathrm{ml}$ of $\mathrm{n}$-hexadecane to the same volume of culture or purified biosurfactant or commercial chemical surfactant solutions in a test tube which was mixed vigorously with vortex for $2 \mathrm{~min}$. The tubes were incubated at $25^{\circ} \mathrm{C}$ and the emulsification index (EI) was determined after a given time $(\mathrm{t})$ according to Equation below:

$$
\mathrm{EI}_{\mathrm{t}}=\left(\frac{\mathrm{H}_{\mathrm{s}}}{\mathrm{H}_{\mathrm{t}}}\right) \times 100
$$

where $\mathrm{He}$ and $\mathrm{Ht}$ are the height of emulsion and total height of the liquid in the tube, respectively. All emulsification indexes were performed in triplicate. To study the emulsion stability the same protocol was used; the emulsification index $[24,25]$.

\subsection{Production of Biosurfactant}

2.7.1. Biosurfactant production by identified yeast strain SS2 grown on various carbon sources

The biosurfactant is produced by cultivation of SS2 yeast strain (Pichia sp.) in a 250ml production medium containing $0.2 \% \mathrm{NaNO}, 0.02 \% \mathrm{KH} 2 \mathrm{PO} 4,0.02 \% \mathrm{MgSO} 4.7 \mathrm{H} 2 \mathrm{O}, 0.1 \%$ Yeast extract, $4 \%$ and $8 \%$ of various carbon sources such as glucose, corn starch, glycerol, coconut oil, and soybean oil in a 500ml Erlenmeyer flask with shaking at $200 \mathrm{rpm}$ for 7 days at $30^{\circ} \mathrm{C}$. Cell culture $(6 \% \mathrm{v} / \mathrm{v})$ was used as inoculums which was an overnight culture, maintained at $\mathrm{pH}$ 4.5. Aliquots of the culture were removed periodically for growth and biosurfactant activity analysis. To determine the optimum concentration of the carbon source, concentrations of $1-8 \%$ were used to determine biosurfactant producing activity. Biosurfactant activity in the culture was determined by measuring the oil displacement activity as described by Morikawa et al.

\subsubsection{Biosurfactant production by identified yeast strain SS2 grown in various nitrogen sources}

The biosurfactant is produced by cultivation of SS2 yeast strain (Pichia sp.) in a $250 \mathrm{ml}$ medium containing $0.02 \% \mathrm{KH}_{2} \mathrm{PO}_{4}, 0.02 \% \mathrm{MgSO} 4.7 \mathrm{H}_{2} \mathrm{O}, 0.1 \%$ Yeast extract, $4 \%$ of soybean oil and various nitrogen sources such as $\mathrm{NH}_{4} \mathrm{NO}_{3},\left(\mathrm{NH}_{4}\right)_{2} \mathrm{SO}_{4}$ and $\mathrm{NaNO}_{3}$ at $0.2 \%$ and $0.4 \%$ in $500 \mathrm{ml}$ flask with $250 \mathrm{ml}$ medium with shaking at $200 \mathrm{rpm}$ for 7 days at $30^{\circ} \mathrm{C}$. Aliquots of the culture were removed periodically for growth and biosurfactant activity analysis. To determine the optimum concentration of the nitrogen source, concentrations of $0.1 \%-0.5 \%$ were used to determine biosurfactant producing activity. Cell culture $(6 \% \mathrm{v} / \mathrm{v})$ was used as inoculums which was overnight culture. Biosurfactant activity in the culture was determined by measuring the oil displacement activity as described by Morikawa et al.

\subsubsection{Effect of $\mathrm{pH}$ on biosurfactant production}

To determine the optimum $\mathrm{pH}$ of the production medium, cells were cultivated in media containing $4 \%$ soybean oil as a carbon source and $0.4 \% \mathrm{NaNO}_{3}$ as a nitrogen source at various $\mathrm{pH}$ levels, ranging from 3.5 to 6.5. It was incubated at $30^{\circ} \mathrm{C}$ with shaking at $200 \mathrm{rpm}$ for 7 days. The supernatant were collected and analyzed for biosurfactant activity every day for 7 days [26]. 


\subsubsection{Production and extraction of Biosurfactant}

Biosurfactant production was analyzed in $1000 \mathrm{ml}$ production medium with $4 \%$ Soybean oil as carbon source and $0.4 \% \mathrm{Na} \mathrm{NO}_{3}$ as nitrogen source with $\mathrm{pH} 5.5$ with shaking at $200 \mathrm{rpm}$ for 7 days at $30^{\circ} \mathrm{C}$. After 7 days cells were removed by centrifugation at $7,500 \mathrm{rpm}$ for $15 \mathrm{~min}$. The supernatants were kept at $4^{\circ} \mathrm{C}$ overnight, after which clear separation of the two phases was observed. The aqueous phase was harvested and extracted 3 times with ethyl acetate. The solvent layer was evaporated to dryness in a vacuum at $40^{\circ} \mathrm{C}$. The crude extracts obtained were weighed and analyzed for biosurfactant activity by oil displacement technique.

\subsection{Microorganism and Identification}

\section{Results}

Among the 50 yeast isolates, only 6 isolates were active for biosurfactants, of which SS2 exhibited the highest activity (Table 1). The morphological and physiological characteristics of the yeast strain SS2 were identified. The results of assimilation test, growth characteristics, and gene sequence analysis suggest that it belongs to the genus Pichia and according to 18Sr RNA- ITS gene sequence analysis, it suggested similarity to the strain Pichia fermentans ATCC 10651 (GQ458040.1).

Table 1: Isolation of Biosurfactant producing yeast strains

\begin{tabular}{|c|c|}
\hline & YEPD \\
\hline Total isolates & 50 \\
\hline Biosurfactant activity & 6 \\
\hline
\end{tabular}

\subsection{Biochemical analysis of SS2 yeast isolate}

The characteristics of yeast strain SS2 grown on differential medium were off-white, oval shaped and smooth colonies. On microscopy, it showed budding yeast like cells (Figure 1). The presence of growth of SS2 isolate in yeast nitrogen base indicated the utilization of carbohydrates including glucose, glycerol, inositol, inulin, lactose, maltose, mannitol, mannose, salicin, sorbitol, sucrose, trehalose and xylose (Table 2).

Figure 1: Microscopic identification of SS2 yeast isolate

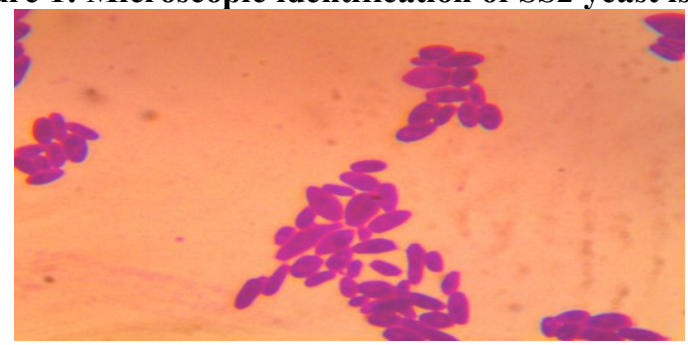

Table 2: Carbohydrate Utilization of SS2 yeast isolate

\begin{tabular}{|c|c|c|}
\hline \multirow{2}{*}{ S.No. } & \multirow{2}{*}{ Experiment } & \multirow{2}{*}{$\begin{array}{c}\text { Isolate SS2 } \\
\text { Growth }\end{array}$} \\
\hline & & \\
\hline 1 & Adonitol & - \\
\hline 2 & L-Arabinose & - \\
\hline 3 & Cellobiose & - \\
\hline 4 & Glucose & ++ \\
\hline 5 & Dulcitol & - \\
\hline 6 & Galactose & - \\
\hline 7 & Glycerol & ++ \\
\hline 8 & Inositol & + \\
\hline 9 & Inulin & + \\
\hline 10 & Lactose & ++ \\
\hline 11 & Maltose & ++ \\
\hline 12 & Mannitol & ++ \\
\hline 13 & Mannose & ++ \\
\hline 14 & Melibiose & - \\
\hline 15 & Raffinose & - \\
\hline 16 & Rhamnose & - \\
\hline 17 & Salicin & + \\
\hline
\end{tabular}


Screening, Gene Sequencing And Biosurfactant Production From Pichia Fermentans Isolated From

\begin{tabular}{|c|c|c|}
\hline 18 & Sorbitol & ++ \\
\hline 19 & Sucrose & ++ \\
\hline 20 & Trehalose & ++ \\
\hline 21 & Xylose & ++ \\
\hline 22 & Blank & - \\
\hline
\end{tabular}

3.3 Identification of SS2 yeast isolate using 18S -ITS sequence of rRNA based molecular technique

Based on the maximum identity score in the Blast $\mathrm{n}$ results, homology and phylogenetic data, SS2 yeast strain belongs to Pichia species and has a maximum score with $92 \%$ identity towards Pichia fermentans strain ATCC 1065 (GQ458040.1) for a a query cover of 99\%. The 18S rRNA forward query gene sequence of the SS2 yeast isolate was compared with the data present in NCBI. Phylogenetic tree was constructed and relationship was determined (Table 3).

Table 3: Query sequence, BLAST results, and Phylogenetic tree - SS2 yeast isolate

\begin{abstract}
Query sequence:
AAGTTAGAGACTTCTCTTGATCTTACGGGTGGTGGTGCATGGCCGTTTTTAGTCCTTGGAGTGATTTGTCTGCTTAATTG

CGATAACGGACGAGACCTTAACCTGCTAAATAGGGCTGCGAGCATCTGCTCGGGTGCTCTTCTTAGAGGGACTATGGGTA

TCAAACCCATGGAAGTTTGAGGCAACAACAGGTCTGTGATGCCCTTAGACGTTCTGGGCCGCACGCGCGCTACACTGACG GAGCCAGCAAGTCCAACCTTGGTCGAGAGGCCCGGGTAATCTCGTGAAACTCCGTCGTGCTGGGGATAGAGCATTGTAAT TTTTGCTCTTCAACGAGGAATTCCTAGTAAGCGCAAGTCATCAGCTTGCGTTGATTACGTCCCTGCCCTTTGTACACACC GCCCGTCGCTACT ACCGATTGAATGGCTTAGTGAGGCTTCAAGATTGGCGCCGCGGGAGGGGCAACTTTCCCATGGGGCC GAGAATCTAGTCAAACTTGGTCATTTAGAGGTCGTAAAAGTCGTAACAAGGTTTCCGTAGGTGAACCTGCGGAAGGATCA TTACTGTGATTTAGTACTACACTGCGTGAGCGGAACGAAAACAACAACACCTAAAATGTGGAATATAGCATATAGTCGAC AAGAGAAATCTACGAAAAACAACAAAACTTTCAACAACGGATCTCTTGGTTCTCGCATCGATGAAGAGCGCAGCGAAATG CGATACCT AGTGTGAAGTGCAGCCATCGTGAATCATCGAGTTCTTGAACGCACATTGCGCCCCTCGGCATTCCGGGGGGC ATGCCTGTTTGAGCGTCGTTTCCATCTTGCGCGTGC
\end{abstract}

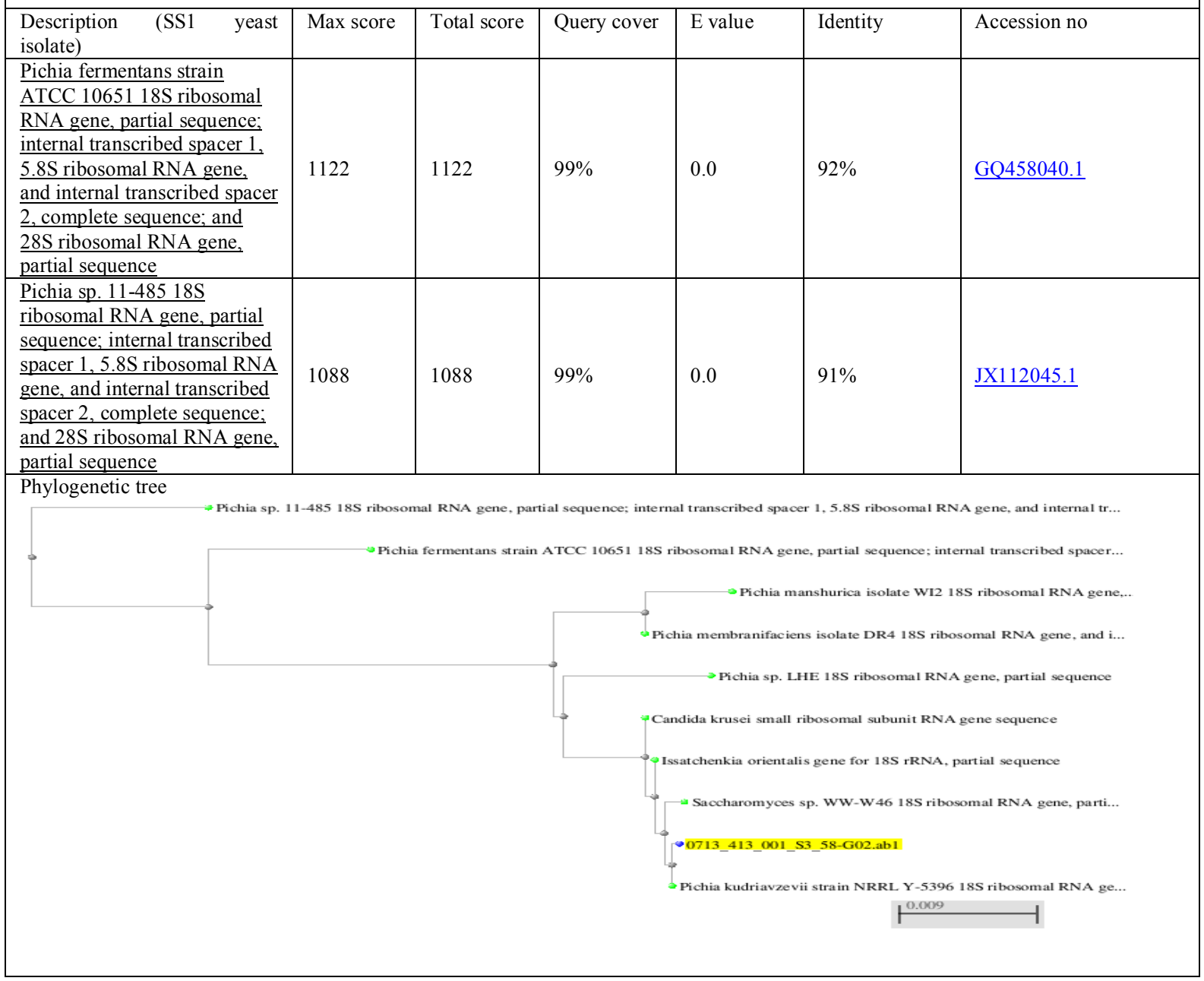




\subsection{Preliminary screening for biosurfactant activity}

As per the gene sequencing results, SS2 yeast isolate exhibited close and comparable similarity with Pichia fermentans. This isolated was then screened for biosurfactant activity which gave an oil clearance diameter of $12 \mathrm{~mm}$ with an interpolated surfactant concentration of 2.77 micrograms. The supernatant of SS2 yeast isolate collapsed on the oily surface and gave a flat drops with scoring system ranging from '+' to '++++' corresponding to partial to complete spreading on the oil surface. In microplate assay screening for yeast isolate SS2, the presence of surfactants caused some wetting at the edge of the well and the fluid surface becomes concave and took the shape of a diverging lens and the concave surface distorted the image of the grid. The optical distortion of the grid provides a qualitative assay for the presence of biosurfactants (Table 4 and Figure 2).The diameter of the clear zone on the oil surface was measured and related to the concentration of biosurfactant by using a standard curve prepared with a commercially available biosurfactant Tween-80 (Sigma, St. Louis, MO). The unknown biosurfactant concentration was determined by comparing with the concentration of the standard surfactant Tween- 80 in various dilutions and a standard graph was plotted. Commercial surfactant Tween-80 exhibited an oil clearance diameter of $12 \mathrm{~mm}$ with a concentration of 2.62 microgram in 1:16 dilution (Figure 3) (Table 5 and 6). The SS2 isolate measured an emulsification index of 50.00 with a height of emulsion $14 \mathrm{~mm}$ after 24 hours. After 120 hours the emulsification index is 61.42 with a height of emulsion $17.2 \mathrm{~mm}$ (Table 7 and Figure 3). The present study showed that the surface activities of biosurfactant yeast species were found to be approximately similar to the commercial surfactant Tween-80. The results suggested that the biosurfactant from Pichia species or strain similar to Pichia fermentans provides excellent emulsification property.

Table 4: Screening of SS2 yeast isolate for Biosurfactant Activity

\begin{tabular}{|c|c|c|c|c|}
\hline S.No. & Culture Isolate & $\begin{array}{c}\text { Oil clearance } \\
\text { diameter (mm) }\end{array}$ & $\begin{array}{c}\text { Presence of } \\
\text { Drop Collapse }\end{array}$ & $\begin{array}{c}\text { Microplate } \\
\text { assay }\end{array}$ \\
\hline 1 & SS1 & $<5$ & - & - \\
\hline $\mathbf{2}$ & SS2 & $\mathbf{1 2}$ & +++ & +++ \\
\hline 3 & SS3 & 5 & +- & + \\
\hline 4 & SS4 & 5.5 & + & + \\
\hline 5 & SS5 & 8 & ++ & + \\
\hline 6 & SS6 & $<2$ & - & - \\
\hline
\end{tabular}

Figure 2 : Biosurfactant Activity by Oil Spreading Technique

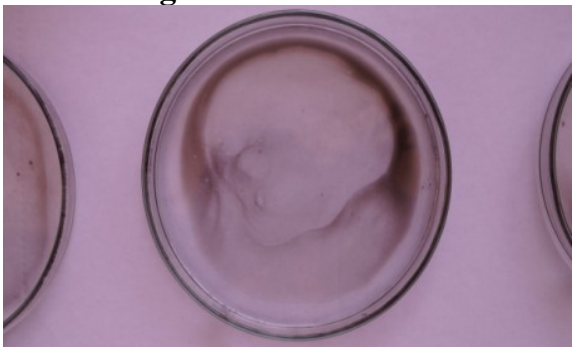

Positive oil displacement

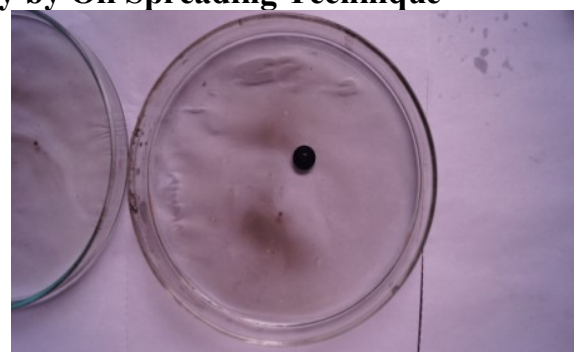

Negative oil displacement

Table 5: Standard Surfactant activity

\begin{tabular}{lll}
\hline Dilution & Tween-80 Concentration & Oil clearance diameter $(\mathbf{m m})$ \\
\hline $1: 1$ & 42.0000 & $>40$ \\
$1: 2$ & 21.0000 & 35 \\
$1: 4$ & 10.5000 & 18 \\
$1: 8$ & 5.25000 & 17 \\
$1: 16$ & 2.62500 & 12 \\
$1: 32$ & 1.31250 & 10 \\
$1: 64$ & 0.65625 & 6 \\
$1: 128$ & 0.32812 & $<6$ \\
\hline
\end{tabular}

Table 6: Interpolated Approximate Concentration of Biosurfactant from Standard Plot

\begin{tabular}{ccc}
\hline Sample Isolate & Concentration $(\boldsymbol{\mu g})$ & Oil Clearance Diameter $(\mathbf{m m})$ \\
\hline SS2 & $\mathbf{2 . 7 7 4 7 8 2}$ & $\mathbf{1 2 . 0 0 0}$ \\
SS5 & 1.655955 & 8.000
\end{tabular}


Figure 3: Determination of Unknown biosurfactant concentration compared with standard Determination of Unknown Biosurfactant concentration
from standart surfactant Tween-80 Concentration from standart surfactant Tween-80 Concentration
(Standard Curve)

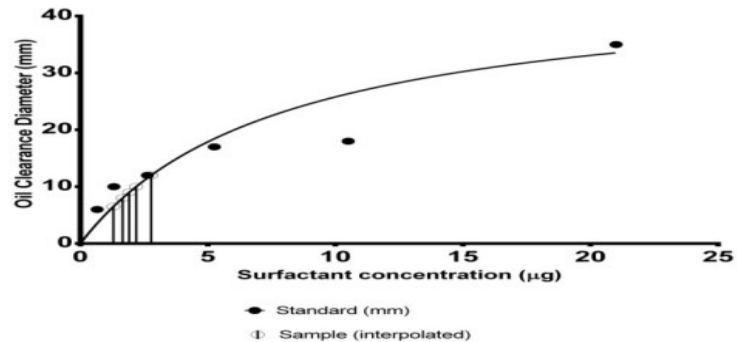

Table 7: Emulsification activity exhibited by SS2 yeast isolate

\begin{tabular}{|l|c|c|c|}
\hline & $\begin{array}{l}\text { Height of emulsion (He) in } \\
\mathrm{mm}\end{array}$ & $\begin{array}{l}\text { Total height of the Liquid (Ht) in } \\
\mathrm{mm}\end{array}$ & Emulsification Index (EI) \\
\hline $0.5 \%$ Tween Standard & 19 & 27.5 & 69.09 \\
\hline Isolate SS2 $(24 \mathrm{hr})$ & 14 & 28 & 50.00 \\
\hline Isolate SS2 (120 hr) & 17.2 & 28 & 61.42 \\
\hline
\end{tabular}

Figure 3: Emulsification activity exhibited by yeast isolate SS2

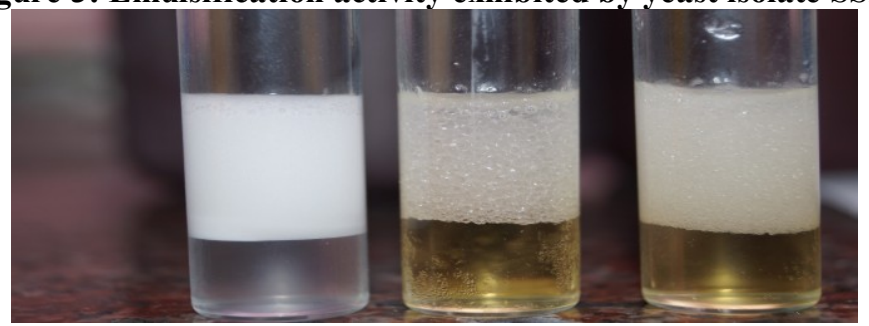

1. $0.5 \%$ Tween Standard 2. Isolate SS2 (24 hr) 3. Isolate SS2 (120 hr)

\subsection{Production of Biosurfactant from SS2 yeast isolate (Pichia fermentans)}

3.5.1. Biosurfactant production and extraction by identified yeast strain SS2 grown in various Carbon and nitrogen sources, and $\mathrm{pH}$ concentration

Six different carbon sources were used: glucose, corn starch, glycerol, crude oil, coconut oil, and soybean oil. These sources were chosen according to the previously reported results [27] and commercially available in areas around Coimbatore. In this study biosurfactant production was determined by biosurfactant activity in terms of oil displacement test. Compared to hydrophilic substrate glycerol, the hydrophobic substrate soybean oil exhibited a maximum oil displacement activity of $9 \mathrm{~mm}$ in diameter. Based on the oil displacement activity, it was found that $8 \%$ soybean oil was the most effective carbon source for the biosurfactant production by the SS2 yeast isolate which has a $92 \%$ similarity to Pichia fermentans. The nitrogen source and its concentration also affected biosurfactant production. It was found that $0.4 \%$ nitrogen source $\mathrm{NaNO}_{3}$ supported biosurfactant production by displacing the oil drop to a diameter of $9 \mathrm{~mm}$ when compared to other nitrogen sources. The influence of the $\mathrm{pH}$ of the culture medium on biosurfactant production was studied in medium containing $8 \%$ soybean oil as carbon source and $0.4 \% \mathrm{NaNO}_{3}$ as nitrogen source. The results exhibited that oil was displaced at a diameter of $9 \mathrm{~mm}$ at $\mathrm{pH} 5.5$ (Table 8). Crude extracts of biosurfactants were prepared from the culture media as described in 'Materials and Methods'. Clear separations of two phases were observed when supernatant was kept undisturbed at $4^{\circ} \mathrm{C}$ overnight. The aqueous phase was harvested, extracted with ethyl acetate, and solvent layer was vacuum dried at $40^{\circ} \mathrm{C}$. The dry crude extract containing biosurfactant obtained was weighed at $6.24 \mathrm{~g} / 1$ which displaced an oil drop at a diameter of $9 \mathrm{~mm}$ (Figure 4).

Table 8: Biosurfactant production by identified yeast strain SS2 grown in various Carbon and nitrogen sources, and $\mathrm{pH}$ concentration

\begin{tabular}{|c|c|c|}
\hline S.No. & Carbon source & Oil Displacement activity (Diameter in \\
mm)
\end{tabular}




\begin{tabular}{|c|c|c|}
\hline 8 & Crude oil 8\% & Nil \\
\hline 9 & Coconut oil 4\% & $<3 \mathrm{~mm}$ \\
\hline 10 & Coconut oil $8 \%$ & $<5 \mathrm{~mm}$ \\
\hline 11 & Soybean oil $4 \%$ & $9 \mathrm{~mm}$ \\
\hline 12 & Soybean oil $8 \%$ & $9 \mathrm{~mm}$ \\
\hline S.No. & Nitrogen source $(0.4 \%)$ & $\begin{array}{l}\text { Oil Displacement activity (Diameter in } \\
\mathbf{m m} \text { ) }\end{array}$ \\
\hline 1 & $0.2 \% \mathrm{NH}_{4} \mathrm{NO}_{3}$ & $<3 \mathrm{~mm}$ \\
\hline 2 & $0.4 \% \mathrm{NH}_{4} \mathrm{NO}_{3}$ & $<5 \mathrm{~mm}$ \\
\hline 3 & $0.2 \%\left(\mathrm{NH}_{4}\right)_{2} \mathrm{SO}_{4}$ & $<4 \mathrm{~mm}$ \\
\hline 4 & $0.4 \%\left(\mathrm{NH}_{4}\right)_{2} \mathrm{SO}_{4}$ & $<5 \mathrm{~mm}$ \\
\hline 5 & $0.2 \% \mathrm{NaNO}_{3}$ & $7 \mathrm{~mm}$ \\
\hline 6 & $0.4 \% \mathrm{NaNO}_{3}$ & $9 \mathrm{~mm}$ \\
\hline S.No. & pH & $\begin{array}{l}\text { Oil Displacement activity (Diameter in } \\
\text { mm) }\end{array}$ \\
\hline 1 & 3.5 & $<5 \mathrm{~mm}$ \\
\hline 2 & 4.5 & $<5 \mathrm{~mm}$ \\
\hline 3 & 5.5 & $9 \mathrm{~mm}$ \\
\hline
\end{tabular}

Figure 4: Production and extraction of biosurfactant

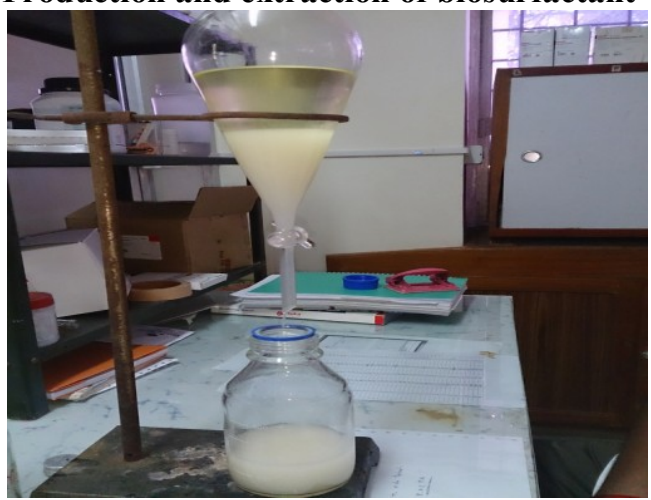

Separation of two phases (gravity separation recovery)

Figure 5: Oil displacement activity of dry crude extract containing biosurfactant

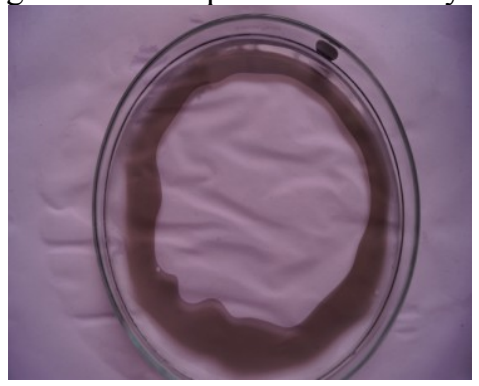

Positive for biosurfactant activity

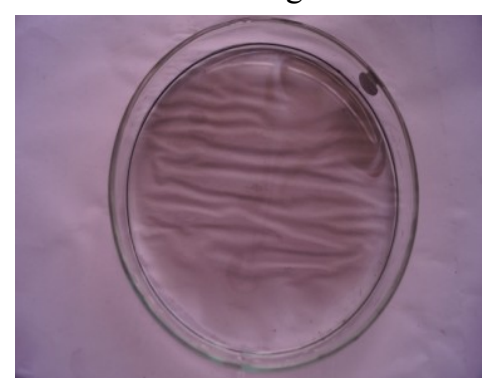

Negative for biosurfactant activity

\section{Discussion}

Dairy industry is one of the major food industries in India [28]. The wastewaters generated from dairy industries contain large amount of fats and oils which gets accumulated in the environment. These wastewaters are considered high in biodegradable carbon and nitrogen sources, its utilization has a low cost fermentative media for the production of biosurfactants. For the screening of biosurfactant producers, enrichment cultures utilizing hydrophobic compounds are used as the sole carbon sources [29]. All results obtained help in reporting a study that examined biosurfactant production by Pichia species which showed $92 \%$ identity with Pichia fermentans isolated from fermented dairy whey waste. A phylogenetic analysis of SS2 yeast isolate was performed to determine how the 18S rRNA of SS2 yeast isolate and its related strain derived during evolution. The homology assay result indicated that the SS2 yeast isolates were in the phylogenetic branch of Pichia species. The identification of SS2 as Pichia fermentans was on the basis of the obtained $92 \%$ sequence similarities for $99 \%$ query [27]. The ITS regions located between highly conserved small $18 \mathrm{~S}$ ribosomal subunit genes in the rRNA operon are known to have sufficient sequence variability to allow identification of the species level for many fungi and yeast. The evolutionary relationships among the sequences were depicted as a phylogenic tree. The branching construction of the tree reflects the degree to which different sequences are related. Sequences that are alike were located as neighboring branches joined together to form a common branch 
beneath them. When the query and reference sequence is $99 \%$ and above, then the unknown isolate would be assigned to reference species. If the percentage similarity is between $95-99 \%$, the unknown isolate would be assigned to the corresponding genus, and when the percentage similarity is less than $95 \%$, the unknown isolate would be assigned to a family. The extraction of the genomic DNA of the isolated yeast was done according to the method suggested by Hoffman \& Winston [30]. For the amplification of the gene, 18S, ITS conserved sequences and a pair of forward and reverse primers was used by Aristogene Private Limited, Bangalore which was also suggested by WHITE et. al [31]. The sequences obtained were compared to the ones deposited in the "NCBI" (National Center for Biotechnology Information). Blast (Basic Local Alignment Search Tools) was used as a tool for the comparison of the sequence [32]. It shows that the phylogenetic relationship between the isolate and other related yeast species. The influences of the concentration of various carbon and nitrogen sources, along with the impact in the culture media at various $\mathrm{pH}$ levels were studied. The aim behind screening of new biosurfactants is to find new structures with strong interfacial activity, high emulsion capacity, and discovery of good production strains with high yields. Growth associated biosurfactant production has a parallel relationship between substrate consumption, growth and biosurfactant production[33]. The enrichment culture provides growth conditions that are very favorable for the SS2 yeast strains to grow and as unfavorable as possible for the competing organisms. Drop collapse assay[34] relies on the destabilization of liquid droplets by surfactants. The stability of those drops is dependent on surfactant concentration and its correlation with surface tension. Based on the results obtained after the study, $8 \%$ soybean oil and $0.4 \% \mathrm{NaNO}_{3}$ can be considered as the best carbon and nitrogen sources with an optimum $\mathrm{pH}$ of 5.5. The findings can be supported by some previous reports which state the soybean oil and $\mathrm{NaNO}_{3}$ with $\mathrm{pH} 5.5$ was the optimum carbon, nitrogen and $\mathrm{pH}$ for biosurfactant production of Pichia anomala. Pichia is a genus of yeasts in the family Saccharomycetaceae with spherical or oblong cells. It is a teleomorph and produce round ascospores during sexual reproduction. The anamorphs of Pichia species are Candida species. One of the Pichia species isolated from fermented whey waste, Pichia fermentans has proved to be attractive yeast for producing biosurfactants and its role in industrial applications.

\section{Conclusion}

Biosurfactants are ecologically accepted, low toxic, biodegradable, and effective than chemical surfactants. Most of the literatures throw light on the production of biosurfactants from bacterial species, but most of the byproducts are inappropriate to be used in industrial, food, or pharmaceutical industries; due to its pathogenic nature. Yeast, being a GRAS (generally regarded as safe) status microorganism, produces higher quantity of biosurfactants when compared to bacterial species. But the cost for its production makes it economically non feasible. Usage of renewable resources or accumulated waste effluents as substrates can be a possible strategy to reduce its production cost and help extend its application in all industries. Also it was recovered by simple and inexpensive techniques such as gravity separation and solvent extraction. In this work, one of the Pichia species was isolated from fermented whey waste which showed $92 \%$ similarity with Pichia fermentans that was screened to detect its ability to produce biosurfactants with soybean oil and $\mathrm{NaNO}_{3}$ as carbon and nitrogen sources.

\section{Acknowledgements}

I thank Mr. Subburaj, Senior Microbiologist at T. Stanes \& Company, Coimbatore and Ms. Vasudha, Director of Aristogene Biosciences, Bangalore, for technical assistance.

\section{References}

[1]. Kitamoto, D., Isoda, H. and Nakahara, T. 2002 A Review of Functions of Glycolipids Biosurfactants-from Energy-Saving Materials to Gene Delivery Carriers, Journal of Bioengineering, 94(3), 187-201.

[2]. Benincasa, M., Contiero, J., Manresa, M.A. and Moraes, I.O. 2002, J. Food Eng., 54:283-288.

[3]. Desai, J. and Banat, I.M. 1997 Microbial Production of Surfactant and Their Commercial Potential, American Society for Microbiology, 61(1), 47-64.

[4]. Khire, J. M. and Khan, M. I. (1994) MEOR: Microbes and the subsurface environment. Enzyme Microb. Tech., 16, 258-259.

[5]. Banat, I. M., Makkar, R. S., and Cameotra, S. S. (2000) Potential commercial applications of microbial surfactants. Appl. Microbiol. Biotechnol., 53, 459-508.

[6]. Banat, I.M. 1995, Bioresour. Technol., 51:1-12.

[7]. Banat, I.M. 1995, Acta Biotechnol., 15:251-267

[8]. O'Connor, L. 2002, Ind. Bioprocessing, 24:10-11

[9]. http://www.transparencymarketresearch.com/biosurfactants-market.html

[10]. Koma, D., Hasumi, F., Yamamoto, E., Ohta, T., Chung, S. Y., and Kubo, M. (2001) Biodegradation of long-chain n-paraffins from waste oil of car engine by Acinetobacter sp. J. Biosci. Bioeng., 91, 94-96

[11]. Hua, Z., Chen, J., Lun, S., and Wang, X. (2003) Influence of biosurfactants produced by Candida antarctica on surface properties of microorganism and biodegradation of n-alkanes. Water Res., 37, 4143-4150.

[12]. Makkar, R.S and Cameotra, S.S. (1998), Production of biosurfactant at mesophilic and thermophilic conditions by a strain of Bacillus subtillis. Journal of Microbiology and Biotechnology. 20, 48-52.

[13]. Felse, P.A.; Shah, V.; Chan, J.; Rao, K.J.; Gross, R.A. (2007). Sophoroplid biosyntesis by Candida bombicola from industrial fatty acid residues. Enzyme Microb. Technol. 40, 316-323. 
[14]. Ewing, B.; Green, P. (1998a). Base-calling of automated sequencer traces using phred. II. Error probabilities, Genome Res. 8:186194.

[15]. Ewing, B.; Hillier, L.; Wendl, M.C.; Green, P. (1998b). Base-calling of automated sequencer traces using phred. I. Accuracy assessment, Genome Res. 8:175-185.

[16]. L.R. Deleu, M. and Paquot, M. (2004), From renewable vegetables resources to microorganisms: new trends in surfactants Compters Rendus Chimie. (Article in press).

[17]. Abu Bakar, F., A.S. Abdulamir, N.Nordin and T.S.Yoke, 2010. Methods for precise molecular detection of probiotic microflora: using adjusted molecular biology protocols, primer sets and PCR assay biotechnology, 9: 25-32.

[18]. Ausubel, F.M., Brent, R., Kingston, R.E., Moore, D.D., Seidmann, J.G., and Struhl, K. (1990) in Current Protocols in Molecular Biology, Vol 2, page A.1.5., John Wiley \& Sons, Inc. New York, NY

[19]. Chen Niu, Hirut Kebede, Dick L. Auld, Jason E. Woodward, Gloria Burow, and Robert J. Wright. A safe inexpensive method to isolate high quality plant and fungal DNA in an open laboratory environment. African Journal of Biotechnology 2008:1.7 (16):2818-22.

[20]. Olmos, A., Bertolini, E. and Cambra M. (2002). Simultaneous and Co-operational amplification (Co-PCR) for detection of plant viruses. J. Virol. Methods 106: 51-59.

[21]. Morikawa M, Hirata Y, Imanaka T. A study on the structure-function relationship of lipopeptide biosurfactants. Biochim Biophys Acta 2000; 1488(3):211-218.

[22]. Bodour A, Miller-Maier R. Application of a modified drop-collapse technique for surfactant quantitation and screening of biosurfactant-producing microorganisms. J Microbiol Methods 1998; 32(3):273-280.

[23]. Vaux D, Cottingham M. Method and apparatus for measuring surface configuration. Patent number WO 2007/039729 A1, 2001.

[24]. Tabatabaee, A., Assadi, M.M., Noohi, A.A. and Sajadian, V.A. 2005 Isolation of Biosurfactant Producing Bacteria from Oil Reservoirs, Iranian Journal of Environment Health Science Engineering, 2(1), 6-12.

[25]. Sarubbo, L.A. 2006 Production and Stability Studies of the Bioemulsifier Obtained from a Strain of Candida glabrata UCP 1002, Journal of Biotechnology, 9(4), 400-406.

[26]. J. Thaniyavaran, T. Chianguthai, P. Sangvanich, et al., Production of Sophrolipid biosurfactant by Pichia anomala, Biosci, Biotechnol, Biochem, 72, 2061-2068 (2008).

[27]. Hu Y, Ju LK. Sophorolipid production from different lipid precursors observed with LC-MS. Enzyme Microb Technol 2001;29:593-601.

[28]. B. D. Tripathi, and A. R. Upadhyay, "Dairy effluent polishing by aquatic macrophytes," Water Air Soil Pollut., 2003, vol. 143, pp. 377- 385 .

[29]. Giani C, Wullbrandt D, Rothert R et al. Hoechst Aktiengesellschaft, Frankfurt am Main. Pseudomonas aeruginosa and its use in a process for the biotechnological preparation of l-Rhamnose. US patent 1997; 5:658-793.

[30]. Hoffman, C. S .and F. Winston. (1987) A ten-minute DNA preparation from yeast efficiently releases autonomous plasmids for transformation of Escherichia coli. Gene 57: 267-272.

[31]. White, T.J.; Bruns, T.; Lee, S.; Taylor, J.W. (1990). Amplification and direct sequencing of fungal ribosomal RNA genes for phylogenetics. In: PCR Protocols: A guide to methods and applications. San Diego: Academic Press, p. 315-322.

[32]. P. P. Bosshard, R. Zbinden, S. Abels, B. Böddinghaus, M.Altwegg and E. C. Böttger. 16S rRNA Gene sequencing versus the API 20 NE Systems and the VITEK 2 ID-GNB Card for Identification of Nonfermenting Gram-Negative Bacteria in the Clinical Laboratory. J. Clin. Microbiol. 2006, 44(4):1359.

[33]. Rodrigues, L.R., Banat, I.M., Teixeira, J.A. and Oliveira, R. 2006, J. Antimicrob. Chemother., 57:609-618

[34]. Jain D, Collins-Thompson D, Lee H et al. A drop-collapsing test for screening surfactant-producing microorganisms. J Microbiol Methods 1991; 13(4):271-279. 